\title{
Study of the Efficacy of Cognitive Behavioral Group Treatment on Anger Rumination and Resilience of Cardiovascular Patients
}

\author{
Kosar Bardideh $^{1}$, Fatemeh Bardideh ${ }^{2} \&$ Keivan Kakabaraee ${ }^{3}$ \\ ${ }^{1}$ Department of Psychology, Kermanshah Branch, Islamic Azad University, Kermanshah, Iran \\ ${ }^{2}$ Department of Plant Breeding, Agriculture Faculty, Kermanshah Branch, Islamic Azad University, Kermanshah, \\ Iran \\ ${ }^{3}$ Department of Psychology, Kermanshah Branch, Islamic Azad University, Kermanshah, Iran \\ Correspondence: Keivan Kakabaraee, Department of Psychology, Kermanshah Branch, Islamic Azad University, \\ Kermanshah, Iran.
}

Received: April 20, 2016 Accepted: January 12, 2017 Online Published: January 31, 2017

doi:10.5539/gjhs.v9n4p163 URL: http://dx.doi.org/10.5539/gjhs.v9n4p163

\begin{abstract}
Introduction and Purpose: The purpose of the present study is to analyze the efficacy of cognitive behavioral group treatment on reducing anger rumination and increasing the resilience of cardiovascular patients.

Methodology: The present study is quasi-experimental and follows a two- group pretest-posttest design. The statistical universe of the present study consists of all cardiovascular patients attending Tehran specialized treatment centers in 2015 for treatment of cardiovascular diseases. In the present study, 40 participants were selected from the research population and they were randomly assigned to two experimental and control groups (20 for experimental group and 20 for control group. For collecting data Sukhodolsky's anger rumination scale questionnaire and Conner, K. M., \& Davidson's resilience scale questionnaire were implemented and for analyzing and examining the data multivariate covariance analysis test and single-variant covariance analysis have been employed.
\end{abstract}

Results: The research findings showed that cognitive behavioral group treatment leads to the reduction of mental rumination and increase of resilience among the group under the study and these results are statistically significant at $0.01(\mathrm{P}>0.01)$.

Conclusion: According to the research finding it can be concluded that cognitive behavioral group treatment has a significant impact on this group and this treatment can be employed as an opposite solution to reduce the symptoms of those suffering from cardiovascular diseases and also to prevent the occurrence of such diseases.

Keywords: cognitive behavioral group treatment, resilience, anger rumination, cardiovascular patients

\section{Introduction}

Cardiovascular diseases are the most common cause of mortality and the most significant cause of breakdown in most of the countries including Iran (Vahedian, Alhani, Ahmadi, \& Kazemnejad, n.d.). In America around 79 million people in other words one third of the adult population suffer from this disease (Rosamond, Flegal, Furie, Go, Greenlund, \& Haase, 2008).

Some studies have focused on the psychological factors efficient in the outbreak of cardiovascular diseases and one of these factors is anger. Researches show the direct relationship between the possibility of being infected by cardiovascular diseases and the rate of anger (Segerstrom, Stanton, \& Shortidge, 2003; Miller, 2005; Boyle, Williams, Mark, Brummett, Siegler, \& Barefoot, 2005; Glynn, Christenfeild, \& Grein, 2007; Key, Campbell, Bacon, \& Gerin, 2008; Chida \& Steptoe, 2009; Lampert et al., 2009; Agha Yousefi \& Shahande, 2012). In fact experiencing the excitement of anger which lasts between 10-15 minute leads to the activation of sympathetic in the body that on one hand increases the blood pressure and more cardiovascular activation and on the other hand weakens physical stamina to confront critical moments (Pedersen \& Denollet, 2006; Williams, O'Connor, Grubb, 
\& O'Carroll, 2012). But the factor which makes the anger as one of the causes of the occurrence of cardiovascular diseases is the anger rumination. Anger rumination is an inevitable and repetitive cognitive process that emerges while experiencing anger and it may accompany with the evaluation of past events. In other words anger rumination can be considered as one of the types of mental rumination which happens after experiencing anger as an abnormal and repetitive process (Sukhodolsky, Golub, \& Cromwell, 2012). Those who ruminates anger experience anger several times in a mental way with all aggressive and imaginative way related to the revenge experience that makes the anger experience last for hours from emotional and cognitive perspective (Denson, 2009). Following that, immunity system show too much activity and his rise of activity of the immunity system leads to overexcitement and consequently more susceptibility. It is certain that anger rumination because of too much arousal and long-term sympathetic system in individuals increase the occurrence of mental and physical diseases (Anestis, Anestis, Selby, \& Joiner, 2009). Studies showed that high anger rumination has a direct relationship with cardiovascular diseases (Closa León, Nouwen, Sheffield, Jaumdally, \& Lip, 2010).

Another investigated psychological structure has shown that have a considerable impact on susceptibility towards mental and physical diseases is resilience (Wright, Masten, \& Narayan, 2013). Resilience is defined as the power to stand in front of stress and return to natural balance after experiencing stressful factors. This concept is in relation with positive excitements that have protective role against mental and physical damages (Bonanno, Galea, Bucciareli, \& Vlahov, 2007). Conner and Davidson define resilience as the ability of the individual in establishing bio-psycho balance in risky conditions where the individual has active role in confronting the negative and unfavorable conditions (Conner \& Davidson, 2003). Resilience is also defined as the confidence of the individual to his abilities to overcome tension, having resistant abilities, self-respect, emotional stability and personal characteristics that increase the social protection by others (Pinquart, 2008). In fact the concept of resilience is based on the fact that despite the fact that some of the people are faced with various risky factors while there is a high chance of the occurrence of disorder in them but they do not get affected by that damage. Accordingly the scholars consider resilience and susceptibility two opposite poles of one continuum. Susceptibility refers to the high probability of the occurrence of negative outcomes against the dangers and resilience refers to the high probability of the occurrence of the positive outcomes in problematic conditions. In fact resilient people possess higher mental health level, more expansive self-control skills, more self-confidence and social protection and less get involved in risky conditions (Zemmerman \& Fergus, 2005). Researches show that resilience lead to faster recuperation and better adaptation with cardiovascular diseases (Kubzansky, Sparrow, Vokonas, \& Kawachi, 2001; Davydov, Stewart, Ritchie, \& Chaudieu, 2010; Fathi, Khayer, \& Atigh, 2012). Various treatment methods to cure the accompanying symptoms of cardiovascular diseases have been created. One of the methods whose efficacy on cardiovascular diseases and the accompanying symptoms and disorders that has been approved is the cognitive behavioral treatment (Saab, Bang, Williams, Powell, Schneiderman, \& Thoresen, 2009; Gary, Dunbar, Higgins, Musselman, \& Smith, 2010; Gulliksson, Burell, Vessby, Lundin, Toss, \& Svärdsudd, 2011; Walters, 2013; Bayazi, Ahadi, Fata, \& Danshsari, 2012; Karimi, Kakabararti, Yazdanbakhsh, \& Moradi, 2015). In cognitive-behavioral treatment the strengths of behavioral treatment and cognitive treatment that is objectivity, evaluation and assessment from one side and the interference of the role of cognition in reconstruction and data interpretation on the other side is simultaneously implemented. In cognitive-behavioral treatment there is such a belief that although the therapist cannot change the life condition of the patient but may be able to change the view of the patient in terms of the life events and the stress caused by them. Therefore, the patient is aided to revise his views in terms of the idealistic criteria and the methods of confronting with the events and to stop criticizing himself and find better ways of handling the conditions. Similarly in this method the patient's beliefs and ambitions in terms of the possibility of controlling stress and efficacious confrontation with problematic conditions improve the self-efficiency and competence feeling of the patient and reduces the inability feeling of the patient and improve the negative feeling of the patient (Carroll \& Rounsanille, 2007). Hosseinian and Khani research showed that the cognitive behavioral treatment is effective on the anger rumination of prisoners of Ardabil (Khani \& Hoseinian, 2015). In addition, the research shows the efficacy of cognitive behavioral treatment on resilience of the people (Edwards, Hurst, Rockman, \& Bober, 2010; Norte et al., 2011; Padesky \& Mooney, 2012).

Although cardiovascular patients are mostly recuperated after operation and treatment and able to continue their normal life but they are still exposed to the relapse of the latent symptoms. One of the ways of reducing the possibility of relapses is to change the life style such as avoiding negative excitements and increasing the resistance against stressful events. Given the aforementioned issues and the fact that no similar study has been conducted so far, the present study intends to answer the principle question: Does cognitive behavioral group 
treatment have a significant relationship with reducing anger rumination and increasing resilience of those suffering from cardiovascular diseases?

\section{Methodology}

The present study is quasi-experimental and follows a two-group pretest-posttest design. The statistical population of the present study consists of all cardiovascular patients attending Tehran specialized treatment centers in 2015. Given the fact that the least mass population considered at experimental studies is considered at 15 persons (Delavar, 2010) in order to increase external reliability 40 eligible individuals at hand were assigned into two groups of experimental and control (20 for the experimental group and 20 for the control group). Research inclusion criteria consists of at least high-school education, age range of 20-60, BMI of lower than 30, lack of using physical and mental drugs and lack of suffering diseases such as diabetes, cancer, etc. It is noteworthy to mention that all the patients participating in the research kept on the therapeutic sessions by the end and none of the groups experienced loss and reduction of subjects with a fixed number of 20 people.

\subsection{Research Instruments}

\section{Anger rumination scale}

Anger rumination scale is a 19-item questionnaire prepared by Sukhodolsky et al., (2001) to measure the tendency to think about current rage contentious situations and remembering the past rage contentious situations (Boyle et al., 2005). The scale questions estimate four sub-scales post-anger thoughts, retaliatory thoughts, anger memories, and knowing the causes in four Likert scales ranging from point one (very little) up to point four (very much). Sukhodolsky et al showed that the explorative factor analysis of 19 scale questions can define $54 \%$ of the total variance. Scale reliability by the use of Cronbach's alpha 0.93 and the reliability by the use of test-retest have been reported at 0.77 (21). Also Maksul et al have reported the Cronbach's alpha of the total point of the scale and sub-scales in the ranges 0.68-0.85 (Maxwell, Sukhodolsky, Chow, \& Wong, 2005). In a study by Besharat and Hossieni nejad Cronbach's alpha coefficient of the questions of anger rumination scale (total score), post anger thoughts, retaliatory thoughts, anger memories, and diagnosing the causes for a 833 people sample of students were respectively calculated at $0.95,0.89,0.83,0.87$, and 0.78 . Correlation coefficient between the scores of 214 of the aforementioned sample at two times with four to six week intervals for anger rumination $\mathrm{r}=0.77$, post anger thoughts $\mathrm{r}=0.79$, retaliatory thoughts $\mathrm{r}=0.83$, anger memories $\mathrm{r}=0.81$, and to diagnose the causes $\mathrm{r}=0.74$ was obtained which was at significance level of $\mathrm{P}<0.001$ (Besharat \& Mohammadmer, 2008).

\section{Conner and Davidson's resilience scale}

This 25 question questionnaire scale was created by Conner and Davidson in 2003 to measure the power resistance against pressure and threat. For each question 5 degree Likert spectrum (never-always) has been considered which is scored from zero (never) to 4 (always) (Walters, 2013). The validity of this questionnaire has been calculated by the use of factor analysis and convergent and divergent validity and the reliability has been achieved by the use of test retest and Cronbach's alpha by the test makers at various groups (normal and at the stake of danger). The reliability of this test via Cronbach's alpha method equals 0.89 and by the retest method 0.87 has been reported. Factor analysis results based on special value was higher than 1 . KMO coefficient was equal to 0.87 and Bartholin's sphericity 2174 and was significant at 0.0001 level (Kordmirzanikoozade, 2009).

\subsection{Data Collection}

After obtaining the required licenses and referring to the medical centers from among those possessing the required features 40 were selected at hand and they were assigned into two experimental and control groups. In order to select patients to participate into the research, they were provided with some explanations on the treatment logic and the research objective while the form of treatment testimony was filled by them and 40 ones were selected among those having the inclusion criteria. After selection, the subjects were randomly placed into two groups of experimental and control. They were also assured that their information would be kept confidential. At the next stage, structure of the questionnaire was explained for the patients and the questionnaires were implemented as the pretest by the patients in a time of 20 minutes. Then the experimental group participants signed a contract to attend the treatment sessions. 8 sessions of group treatment once a week and every session for 120 minutes were conducted by the author. After the end of the treatment sessions in order to measure the dependent variables the post-test stage was administered. Finally the obtained data from pretest and post test were analyzed and examined by the use of SPSS-19 and Multiple Variable Covariance Test (in order to analyze the effect of 
treatment on anger rumination and corresponding factors) MANCOVA and (in order to analyze the effect of treatment on single variable of tolerance) ANCOVA were applied.

\subsection{Interference Method}

Table 1. Content of cognitive behavioral treatment group treatment session on anger rumination and resilience

\begin{tabular}{|c|c|}
\hline Session & Session content \\
\hline 1 & $\begin{array}{l}\text { Demographic features, anger rumination scale and resilience } \\
\text { scale questionnaires were handed to participants at this } \\
\text { session rules and process of group, interactional identity of } \\
\text { the three groups, behavior and physiology were discussed. }\end{array}$ \\
\hline 2 & $\begin{array}{l}\text { Defining principle aspects of anger rumination, automatic } \\
\text { thoughts and how to identify them, cognitive distortions or } \\
\text { major rational errors, and their abilities in identifying such } \\
\text { mental errors, presenting the concept of resilience and } \\
\text { identifying the mental pressure and conceptualizing problem } \\
\text { and determining the problematic issues, identifying the } \\
\text { internal control supportive factors and self-esteem against } \\
\text { stressful factors }\end{array}$ \\
\hline 3 & $\begin{array}{l}\text { Introducing the model of attending to thoughts and beliefs and } \\
\text { attention to automatic thoughts before excitements, attention } \\
\text { to physical an mental signs, attention to thoughts and beliefs } \\
\text { before aggression and attention to the behavior after the } \\
\text { thought, identifying the internal supportive factors optimism } \\
\text { and social support against stressful factors }\end{array}$ \\
\hline 4 & $\begin{array}{l}\text { Introducing behavioral consequences and emotional thoughts, } \\
\text { the relationship between schema and the automatic thoughts, } \\
\text { identifying schema by the use of vertical pointer method, } \\
\text { identifying internal supportive factors of responsibility } \\
\text { against stressful factors }\end{array}$ \\
\hline 5 & $\begin{array}{l}\text { Introducing main list of beliefs, map reading, ranking, mental } \\
\text { distress units, objective analysis, familiarity with ways of } \\
\text { creating resilience, self-esteem improvement, and } \\
\text { self-cognizance }\end{array}$ \\
\hline 6 & $\begin{array}{l}\text { Introducing rational analysis of subjects, anger hierarchy } \\
\text { arrangement, familiarity with establishing and creating } \\
\text { purposeful resilience and pragmatism }\end{array}$ \\
\hline 7 & $\begin{array}{l}\text { Introducing self-punishment and self-rewarding, preserving } \\
\text { approaches, familiarity with methods of establishing } \\
\text { resilience and developing self control }\end{array}$ \\
\hline 8 & $\begin{array}{l}\text { Analysis of the development and the fulfillment of the } \\
\text { participants' goals, teaching how to make use of the learning } \\
\text { in real life, analysis of the unfinished tasks of the participants, } \\
\text { study of the feelings of the participants about the end of the } \\
\text { sessions, administration of the posttest }\end{array}$ \\
\hline
\end{tabular}




\section{Results}

The demographic findings of present research showed that $70 \%$ of the experimental group members (14 people) were male and $30 \%$ ( 6 people) were female. In addition, in terms of educational level, $15 \%$ ( 3 people), $25 \%$ (5 people), $40 \%$ ( 8 people) and 20\% (4 people) were graduated in high school, associate, bachelor and master or higher degrees, respectively. In the control group, $65 \%$ of the members ( 13 people) and $35 \%$ ( 7 people) were males and females. Accordingly, in terms of educational level, $20 \%$ (4 people), $30 \%$ (6 people), $35 \%$ ( 7 people) and $15 \%$ (3 people) were graduated in high school, associate, bachelor and master or higher degrees, respectively.

As it can be seen at Table 2 the mean and standard deviation of the variables under the study have been presented.

Table 2. Mean and standard deviation of variables of anger rumination and resilience at experimental and control groups

\begin{tabular}{|c|c|c|c|c|c|c|}
\hline & & \multicolumn{2}{|c|}{ Experimental group } & \multicolumn{2}{|c|}{ Control group } & \multirow{2}{*}{$\mathrm{P}$} \\
\hline & & Mean & Standard deviation & Mean & SD & \\
\hline \multirow[t]{2}{*}{ Post anger thoughts } & Pretest & 24.14 & 71.4 & 25.13 & 55.4 & 0.385 \\
\hline & Posttest & 19.10 & 66.4 & 10.13 & 91.3 & $\mathrm{P}<0.001$ \\
\hline \multirow[t]{2}{*}{ Anger memories } & Pretest & 52.13 & 22.4 & 41.14 & 66.4 & 0.421 \\
\hline & Posttest & 00.10 & 46.4 & 13.13 & 02.3 & $\mathrm{P}<0.001$ \\
\hline \multirow[t]{2}{*}{ Retaliatory thoughts } & Pretest & 21.12 & 07.4 & 07.13 & 29.3 & 0.448 \\
\hline & Posttest & 63.8 & 22.3 & 86.14 & 11.4 & $\mathrm{P}<0.001$ \\
\hline \multirow[t]{2}{*}{ Indentifying the causes } & Pretest & 50.10 & 99.4 & 88.12 & 25.3 & 0.615 \\
\hline & Posttest & 89.7 & 13.4 & 00.13 & 11.3 & $\mathrm{P}<0.001$ \\
\hline \multirow{2}{*}{ Resilience } & Pretest & 14.50 & 78.5 & 28.53 & 00.6 & 0.728 \\
\hline & Posttest & 41.72 & 02.4 & 69.57 & 84.4 & $\mathrm{P}<0.001$ \\
\hline
\end{tabular}

Before the application of covariance analysis parametric test to determine the cognitive behavioral treatment on anger rumination, variance congruity presumption was analyzed by Luvin test. On the basis of the results the variance homogeneity presumption at the variables under the study were approved in both groups. This test was not significant for any of the variables and as a result the use of parametric tests was considered permitted. To analyze the homogeneity of the variance presumption Mbox test was employed and the results showed that the amount of the box is not significant and the indifference presumption of variables exist between the variances $(\mathrm{P}=0.059, \mathrm{~F}=1.43, \mathrm{BOX}=93.48)$. Wilks Lambda test results $\mathrm{P}=0.0001, \mathrm{~F}=38.63)$ also permit the use of multiple variable covariance analysis. These results show that among the experimental and control group there is a significant relationship at least between one of the dependent variables. 
Table 3. Multi variable covariance analysis significance test results on anger rumination in experimental and control group

\begin{tabular}{llllll}
\hline Dependent variables & Sum of Squares & Degree of Freedom & Mean square & F & P \\
\hline Post anger thoughts & 35.43 & 1 & 35.43 & 88.15 & $\mathrm{P}<0.001$ \\
Anger memories & 017.58 & 1 & 017.58 & 44.23 & $\mathrm{P}<0.001$ \\
Retaliatory thought & 4.101 & 1 & 4.101 & 45.27 & $\mathrm{P}<0.001$ \\
Identifying the causes & 06.60 & 1 & 06.60 & 84.20 & $\mathrm{P}<0.001$ \\
\hline
\end{tabular}

As can be seen at Table 3 a significant relationship has been obtained between post anger thoughts $(\mathrm{F}=15.88)$, anger memories $(\mathrm{F}=23.44)$, retaliatory thoughts $(\mathrm{F}=27.45)$, and identifying the causes $(\mathrm{F}=20.84)$ at both experimental and control groups $(\mathrm{P}<0.001)$. In other words cognitive behavioral treatment has lead to the improvement of anger rumination variable at posttest stage among experimental group. Before the application of covariance analysis parametric test to determine the cognitive behavioral treatment on resilience, variance congruity presumption was analyzed by Luvin test. On the basis of the results the variance homogeneity presumption at the variables under the study were approved in both groups. This test was not significant for any of the variables and as a result the use of parametric tests was considered permitted.

Table 4. Single variable covariance analysis test to determine the efficacy of cognitive behavioral treatment on resilience

\begin{tabular}{llllll}
\hline Source of changes & Sum of Squares & Degree of Freedom & Mean square & F & P \\
\hline Impact of interference & 434.36 & 1 & 434.36 & 14.82 & 0.002 \\
Impact of pretest & 514.15 & 1 & 514.15 & 16.02 & 0.001 \\
Error & 357.48 & 37 & 78.14 & & \\
Total & 54298.000 & 40 & & & \\
\hline
\end{tabular}

As can be seen a Table 4 resilience after the pretest impact with $(\mathrm{F}=16.02)$ is at $(\mathrm{P}<0.01)$ significance level. The aforementioned findings show that cognitive behavioral treatment as an interference program has been efficient at improving resilience at experimental group.

\section{Discussion and Conclusion}

The purpose of the present study was to investigate the efficacy of cognitive behavioral group treatment on anger rumination and resilience among the patients suffering from cardiovascular disorders. The research findings showed that cognitive behavioral treatment leads to the reduction of anger rumination variable among cardiovascular patients. This finding is in congruence with that of Khani and Hosseinian (Khani \& Hoseinian, 2015) which showed that cognitive behavioral treatment leads to the reduction of anger rumination among the inmates at prison. To explain the efficacy of the cognitive behavioral group treatment it should be stated that in this perspective the conversion of the inaccurate and faulty way of behavior is the most direct way of diverting excitements and faulty behaviors. Therefore in this perspective the participants become aware of the impact of cognition on emotions and their behaviors. They learn to identify their automatic negative thoughts and rational errors at rage contentious moments and by implementing vertical arrow method get hold of main negative schema that create anger in them, making note of their opposite beliefs and their interpretation in another way reform their schema anew. As a result the change of deficient schema and cognitive reformation leads to the reduction of experiencing the excitement of anger. Besides that the use of guided imaginative relation behavioral methods, mental change and anger hierarchy arrangement leads to the reduction of emotional excitement (Lawrence \& Blum, 
2007). In cognitive-behavioral view in terms of the anger there is a concept that anger reaction because of the insufficient cognitive structure and distorted is determined as a result the change and correction of individual behavior and cognition at anger contention situations leads to the change and correction of the behavior (Cox \& Harrison, 2008). In fact in this type of the treatment by guiding the patients towards identifying automatic thoughts and establishing discussion and mutual understanding they are encouraged towards change of their thoughts and ultimately their feelings that at the end of the educational program patients were able to achieve cognition, perspective, and change of perspective in terms of the views and confrontation of emotions and sensation (Mijolla, Mijolla-Mellor, Perron, \& Golse, 2005). Therefore, it can be concluded that different programs at cognitive behavioral treatment not only leads to the reduction of emotional disorders of the patients after the medical interference but also the rate of some of the factors such as anger in these patients have reduced and also the cognitive behavioral treatment by the change of life style of the patients and change of the behavioral structure and psychological behavior of the cardiovascular patients major steps have been taken towards the improvement of the patients and the reduction of risky factors among cardiac patients.

Similarly, the results showed that the cognitive behavioral group treatment leads to the rise of resilience among cardiovascular patients. This finding is in line with the findings of researches which showed that cognitive behavioral treatment increases the resilience (Edwards et al., 2010; Norte et al., 2011; Padesky \& Mooney, 2012). To explain this finding it can be stated that cognitive behavioral treatment causes people before in an emotional, quick and without benefiting from personal cognitive abilities with a positive and accurate estimation of the present conditions find the rational solutions and decisions. In other words, this treatments causes people get actively engaged in daily life and in the face of problems try all possible solutions to solve the problems before dealing with them via a fixed and predetermined form have a comprehensive and sharp look and by multi dimensional analysis of the issues make innovative decisions. In these situations when people get rid of the obstacles and problems by making apposite decisions their psychological and resilience capacity in the face of life problems increases (Reivich \& Shatte, 2002). In other words, cognitive behavioral treatment enables people to establish a balanced biological, mental and social relationship with life conditions particularly risky situations. In case this confrontation process with risky situations accompanies making rational and accurate decisions several times and consecutively over the life span resilience and its resistance would increase at different situations. This consequently will cause satisfaction, competence, strong invective, and better adaptation with various situations of life. In fact the education of various basic skills of cognitive behavioral treatment to people cause people in various situations by considering the current condition from different vantage points without losing control over behavioral and emotional disposition try to give rational and accurate solutions to solve his problems (Kuyken, Padesky, \& Dudley, 2009). Since at treatment sessions skills and techniques such as though injection, though stoppage, détente dialogs, beneficial analysis, problem solving skill, positive self-talk are used after a couple of educational sessions on one hand the negative automatic thoughts of the patient converts to purposeful thought which are more adaptable with objective realities and their cognitive processing gets more rational and on the other hand the patient gets reinforced by coping skills such as problem solving, behavior management, assertive training, self-expression, and interpersonal skills. Here it is essential to mention the fact that the purpose of cognitive behavioral treatment is to create an archive of flexible and integrated coping behaviors which are sensitive to all stressful situations (Mooney \& Padesky, 2001).

\section{Conclusion}

It can be concluded that since the cardiovascular disease is one of the leading causes of death and morbidity in the world and impose large costs on society, preventing, reducing contributing factors and increasing protective factors of the disease is extremely necessary and important. Thus, according to the findings, it could be explained that group behavior cognitive therapy plays a major role in reducing risk factors and increasing protective factors of this disorder and it is it is hoped that the results of this research consider as strategy for the prevention and treatment of these patients. In the end, it should be noted that such limitations points to the equality of evaluator and therapist, evaluating different types of cardiovascular disease and lack of follow up period. In this regard it is recommended to recognize type of cardiovascular disease and consider the follow-up stage as well.

In fact by the use of this method we can create a feeling of ability, efficiency, and the ability to cope with life and required ability to impose on any impact or influence on the events and situations. As a general conclusion it can be 
stated that since cardiovascular diseases are one of the main causes of mortality in the world and impose a lot of expense on the society, prevention of its occurrence, reducing the preparatory factors, and rise of security factors of these patients are very essential and significant. Therefore, on the basis of the research findings it can be stated that cognitive behavioral group treatment has a significant role in reducing risk factors and increasing the protective factors of this disorder and it is expected that the research findings provide a solution to prevent and treat these patients.

Any research is faced with limitations to reach achievements which should be considered. The present research sample was limited to Tehran which influences the generalization of the research findings to some extent. And the same rater and trainer, analyzing all types of cardiovascular diseases simultaneously without differentiating them and lack of follow-up period are among the limitations of the present study. As delimitation it is suggested to administer this research in other regions and compare the findings. Similarly it is suggested to perform the interference stage by a different person and include the follow-up stage to the future researches.

\section{Competing Interests Statement}

The authors declare that there is no conflict of interests regarding the publication of this paper.

\section{References}

Agha Yousefi, A., \& Shahande, M. (2012). Relationship between Anger and hardiness and quality of life in coronary artery disease. Health Psychology, 2, 39-49.

Anestis, M. D., Anestis, J. C., Selby, E A., \& Joiner, T. E. (2009). Anger rumination across forms of aggression. Personality and Individual Differences, 42, 192-196. https://doi.org/10.1016/j.paid.2008.09.026

Bayazi, M., Ahadi, H., Fata, L., \& Danshsari, S. H. (2012). The effectiveness of a short cognitive behavioral group intervention on depression, anxiety and stress in patients with chronic coronary heart disease: A randomized controlled trail. Journal of Fundamentals of Mental Health, 14(53), 110-121.

Besharat, M., \& Mohammadmer, R. (2008). Evaluate the psychometric properties of the questionnaire anger rumination. Journal of School of Nursing and Midwifer, 19(65), 36-43

Bonanno, G. A., Galea, S., Bucciareli, A. \& Vlahov, D. (2007). What predicts psychological resilience after disaster? The role of demographics, resources, and life stress. Journal of Consulting and Clinical Psychology, 75(5), 671-682. https://doi.org/10.1037/0022-006X.75.5.671

Boyle, S. H., Williams, R. B., Mark, D. B., Brummett, B. H., Siegler, I. C., \& Barefoot, J. C. (2005), Hostility, age, and mortality in a sample of cardiac patients. American Journal of Cardiology, 96, 64-66. https://doi.org/10.1016/j.amjcard.2005.02.046

Carroll, K. M., \& Rounsanille, B. J. (2007). A vision of the next generation of Behavioral therapies research in the addictions. Addiction, 102, 50-862. https://doi.org/10.1111/j.1360-0443.2007.01798.x

Chida, Y., \& Steptoe, A. (2009). The Association of Anger and Hostility with future Coronary Heart Disease: a Meta- Analytic Review of Prospective Evidence. Journal of the American College of Cardiology, 53, 936-946. https://doi.org/10.1016/j.jacc.2008.11.044

Closa León, T., Nouwen, A., Sheffield, D., Jaumdally, R., \& Lip, G. Y. (2010). Anger rumination, social support, and cardiac symptoms in patients undergoing angiography. $\mathrm{Br} J$ Health Psychol, 15(4), 841-57. https://doi.org/10.1348/135910710X491360

Conner, K. M., \& Davidson, J. R. T. (2003). Development of a new resiliency scale: The Conner - Davidson Resilience Scale (CD- RISC). Journal of Depression and Anexiety, 18, 76-82. https://doi.org/10.1002/da.10113

Cox, D., \& Harrison, D. (2008). Models of anger: contributions psychophysiology, neuropsychology and cognitive behavioral perspective. Journal of brain struct funct, 212(3), 371-385.

Davydov, D. M., Stewart, R., Ritchie, K., Chaudieu, I. (2010). Resilience and mental health. Clinical Psychology 
Review, 30, 481. https://doi.org/10.1016/j.cpr.2010.03.003

Delavar, A. (2010). Theoretical and practical research in the humanities and social sciences. Tehran, Roshd Publication.

Denson, T. F. (2009). Angry rumination and the self-regulation of aggression. In J. P. Forgas, R. F. Baumeister, D. M. Tice. (editors), the Psychology of self-regulation. New York, NY, US: Psychology Press: 233-48.

Edwards, S., Hurst, C., Rockman, P., \& Bober, T. (2010). Building resident resilience: Using mindfulness, cognitive behavioural therapy (CBT) and solution-focused therapy to teach residents stress management skills. International Conference on Residency Education.

Fathi, A., Khayer, M., \& Atigh, M. (2012). The relationship between self-efficacy and quality of life due to the mediating role of resiliency among cardiovascular patients. Methods and psychological models Journal, 2, 109-122.

Gary, R. A., Dunbar, S. B., Higgins, M. K., Musselman, D. L., \& Smith, A. L. (2010). Combined exercise and cognitive behavioral therapy improves outcomes in patients with heart failure. J Psychosom Res, 69, 119-131. https://doi.org/10.1016/j.jpsychores.2010.01.013

Glynn, L. M., Christenfeild, N., \& Grein, W. (2007). Recreating cardiovascular responses with rumination: The effecta of delay between harassment and its recall. International Journal of Psychophysiology, 66, 135-140. https://doi.org/10.1016/j.jpsycho.2007.03.018

Gulliksson, M; Burell, G; Vessby, B., Lundin, L., Toss, H., \& Svärdsudd, K. (2011). Randomized controlled trial of cognitive behavioral therapy vs standard treatment to prevent recurrent cardiovascular events in patients with coronary heart disease: Secondary Prevention in Uppsala Primary Health Care project (SUPRIM). Arch Intern Med., 171(2), 134-140. https://doi.org/10.1001/archinternmed.2010.510

Karimi, S., Kakabararti, K., Yazdanbakhsh, K., \& Moradi, G. H. (2015).The effectiveness of cognitive behavior therapy on cardiovascular patient's mental well-being. Monthly Journal of Kermanshah University of Medical Sciences, 18(3), 147-157.

Key, B. L., Campbell, T. S., Bacon, S. L., \& Gerin, W. (2008). The influence of trait and state rumination on cardiovascular recovery from a negative emotional stressor. Journal of Behavioral Medicine, 31, 237-248. https://doi.org/10.1007/s10865-008-9152-9

Khani, A., \& Hoseinian, F. (2015). The effectiveness of cognitive-behavioral therapy in reducing anger and anger rumination in Ardabil Prison. Psychology growth, 3(9), 73-91.

Kordmirzanikoozade, E. (2009). Modeling bio-psycho-spiritual substance abusers and program-based interventions to promote resilience and positive psychology, cognitive narratology. $\mathrm{PhD}$ thesis Of Psychology, Allame Tabatabaee University, Tehran, Iran.

Kubzansky, L. D., Sparrow, D., Vokonas, P., \& Kawachi, I. (2001). Is the glass half empty or full? A Prospective study of optimism and coronary heart disease in the normative aging study. Psychosomatic Medicine, 63, 910-6. https://doi.org/10.1097/00006842-200111000-00009

Kuyken, W., Padesky, C. A., \& Dudley, R. (2009). Collaborative case conceptualization: Working effectively with patients in cognitive behavioral therapy. New York: Guilford.

Lampert, R., Shusterman, V., Burg, M., McPherson, C., Batsford, W., Gold-berg, A., et al. (2009), Anger-induced T-wave alternans predicts future ventricular arrhythmias in patients with implantable cardioverter-defibrillators. Journal of the American College of Cardiology, 53, 774-778. https://doi.org/10.1016/j.jacc.2008.10.053

Lawrence, D., \& Blum, L. D. (2007). Psychodynamics of postpartum depression. Journal of Psychoanalytic Psychology, 24(1), 45-62. https://doi.org/10.1037/0736-9735.24.1.45

Maxwell, J. P., Sukhodolsky, D. G., Chow, C. C. F., \& Wong, C. F. C. (2005). Anger rumination in Hong Kong and 
Great Britain: Validation of the scale and a cross-cultural comparison. Personality and Individual Differences, 39, 1147-1157. https://doi.org/10.1016/j.paid.2005.03.022

Mijolla, D. A., Mijolla-Mellor, S. D., Perron, R., \& Golse, B. (2005). International Dictionary of Psychoanalysis. Paris. The French Ministry of Culture-National Book Center. Printed in the United States of America

Miller, M. C. (2005). Questions \& answers: What is type D personality? Harvard Health Letter, 22(8): 1-8

Mooney, K. A., \& Padesky, C.A. (2001). Creative developments in cognitive therapy. One-day workshop presented at the World Congress of Behavioral and Cognitive Therapies, Vancouver, Canada.

Norte, C. E., Souza, G. G., Pedrozo, A. L., Mendonça-de-Souza, A. C. F., Figueir, I., Volchan, L., \& Ventur, V. (2011). Impact of cognitive-behavior therapy on resilience-related neurobiological factors. Rev Psiq Clín, $38(1), 43-45$.

Padesky, C. A., \& Mooney, K. A. (2012). Strengths-Based Cognitive-Behavioural Therapy: A Four-Step Model to Build Resilience. Clin. Psychol. Psychother, 19, 283-290. https://doi.org/10.1002/cpp.1795

Pedersen, S. S., \& Denollet, J. (2006), Is Type D personality here to stay? emerging evidence across cardiovascular-disease patient groups. Current Cardiolog Reviews, 2, 205-213. https://doi.org/10.2174/157340306778019441

Pinquart, M. (2008). Moderating effect of dispositional resilience on association between hassles and psychological distress. J Appl Dev Psychol, 23, 1-8.

Reivich, K., \& Shatte, A. (2002). The resilience factor: 7 keys to finding your inner strength and overcoming life's hurdles. New York: Broadway Books

Rosamond, W., Flegal, K., Furie, K., Go, A., Greenlund, K., \& Haase, N. (2008). American heart association statistics committee and stroke statistics subcommittee. Heart disease and stroke statistics. Update: a report from the American Heart Association Statistics Committee and Stroke Statistics Subcommittee. Circulation, $117,25-146$.

Saab, P. G., Bang, H., Williams, R. B., Powell, L. H., Schneiderman, N., Thoresen, C. The impact of cognitive behavioral group training on event-free survival in patients with myocardial infarction: the ENRICHD experience. J Psychosom Res, 67(1), 47-56. https://doi.org/10.1016/j.jpsychores.2009.01.015

Segerstrom, S. C., Stanton, A. L., \& Shortidge, B. E. (2003). A multidimensional structure for repetitive thought: what's on your mind, and how, and how much? Journal of Personality and Social Psychology, 85, 909-921. https://doi.org/10.1037/0022-3514.85.5.909

Sukhodolsky, D. G., Golub, A., \& Cromwell, E. N. (22001). Development and validation of the Anger Rumination $\begin{array}{llll}\text { Scale. Personality and Individual } & \text { Differences, }\end{array}$ https://doi.org/10.1016/S0191-8869(00)00171-9,

Vahedian, A., Alhani, F., Ahmadi, F., \& Kazemnejad, A. (n.d.). [Effect of family- centered empowerment model on the life style of myocardial infarction patients]. J Tehran Special Care Nurs, 2(4), 127-32.

Walters, K. (2013). Motivational Interviewing and Cognitive Behavioral Therapy-based Intervention for Cardiovascular Disease Prevention Amongst American Indians With Diabetic and Depressive Symptom. Thesis of Psychology, University of Washington, USA

Williams, L., O'Connor, R., Grubb, N., \& O'Carroll, R. (2012). Type D personality and three-monthpsychosocial outcomes among patients post-myocardial infarction. Journal of Psychosomatic Research, 72, 422-426. https://doi.org/10.1016/j.jpsychores.2012.02.007

Wright, M., Masten, A. S., \& Narayan, A. J. (2013). Resilience processes in development: Four waves of research on positive adaptation in the context of adversity. In S. Goldstein and R.B. Brooks (eds.), Handbook of Resilience in Children (pp. 15-37). New York: Springer. https://doi.org/10.1007/978-1-4614-3661-4_2 
Zemmerman, M. A., \& Fergus, S. (2005). Adolescent resilience: A framework for understanding healthy development in the face of risk. Pro quest health and medical, 25(5), 271-282.

\section{Copyrights}

Copyright for this article is retained by the author(s), with first publication rights granted to the journal.

This is an open-access article distributed under the terms and conditions of the Creative Commons Attribution license (http://creativecommons.org/licenses/by/4.0/). 